\title{
Estimation and Comparative Analysis of Environmental Efficiency in China, with and without Consideration of Haze
}

\author{
Dongdong $\mathrm{Ma}^{1,2}$, Feng $\mathrm{He}^{2 *}$, Guifang $\mathrm{Li}^{3}$, Lili Chen ${ }^{2}$ \\ ${ }^{1}$ School of Economics, Henan University of Economics and Law, Zhengzhou 450046, China \\ ${ }^{2}$ Donlinks School of Economics and Management, University of Science and Technology Beijing, \\ Beijing 100083, China \\ ${ }^{3}$ School of Economics, Renmin University of China, Beijing 100872, China
}

Received: 4 May 2017

Accepted: 15 June 2017

\begin{abstract}
This paper aims to introduce the new constraints of PM2.5 into the environmental efficiency research framework, based on the provincial panel data of China during 2001-12. The authors examine environmental efficiency with and without consideration of PM2.5, conduct hypothesis tests on these environmental efficiencies, and analyze the energy savings and haze reduction. The results indicate that the overall environmental efficiency score is inefficient. The average environmental efficiency scores are 0.706 and 0.867 with and without the consideration of PM2.5, respectively, and omitting PM2.5 would result in biased environmental efficiency change. In addition, empirical analysis shows that there is an unbalanced regional development and significant differences among provinces in environmental efficiency. Last but not the least, the potential savings of energy, water, and regional haze reduction average $24.26 \%$, $39.16 \%$, and $26.49 \%$, respectively.
\end{abstract}

Keywords: haze, SBM-undesirable model, PM2.5, environmental efficiency, haze reduction potential

\section{Introduction}

Air pollution in China has become increasingly serious with rapid economic growth at an average annual rate of $10 \%$ since the implementation of economic reform and the opening of the economy in 1978. Data show that China was covered by haze for around 35.9 days in 2013, which is 18.3 days more than in 2012 [1]. The death toll has become higher and higher due to respiratory and cardiovascular diseases because of the continuing haze

*e-mail: hefeng@manage.ustb.edu.cn outbreak. Data show that the number of deaths caused by outdoor air pollution were estimated conservatively as 350,000 500,000 each year in China. The cost of health caused by air pollution has accounted for 1.16$3.8 \%$ of GDP [2]. At the same time, haze has become one of the biggest obstacles to attracting foreign investment, talent, and tourists. Other countries also suffer from particulate pollution, for example PM10 particulate matter concentration is a substantial and as yet unresolved problem in the area of Warsaw, Poland [3-4]; PM2.5 particulate matter is also a large concern in many other European countries, particularly Switzerland, Belgium, Germany, Italy, Norway, and the Czech Republic [5-6]; 
and England and Wales, the United States, and Japan also have experienced long periods of air pollution [7-9]. The Indian government has launched a new air quality index in an attempt to tackle the highest PM2.5 concentrations of air pollution in India [10]. There is no doubt that there exists a certain connection between haze, energy structure, and industrial development [11], but is there a difference for environmental efficiency with and without the consideration of haze? Moreover, how much energy savings and haze reduction potentials are there in each province? Therefore, it is important for China to solve those problems of high input, high energy consumption, high pollution, and high emission, and to turn toward the economic development mode of high output, low energy consumption, low pollution, and low emission.

How to estimate environmental efficiency has always been a hot topic in the economic field - especially in China since 2008. Much literature concentrates on the traditional double input variables and economic output on environmental efficiency research. The options of the traditional double-input variables are relatively limited by labor and capital [12]. With the emphasis on environmental protection and energy conservation, some researchers have begun to put energy consumption in input variables [13-14], other researchers also just introduced total water consumption into input variables [15-16]. Outputs can be mainly divided into economic output and environmental output. Economic output was mainly regional GDP and environmental output mainly lies in the choice of pollutants, including sulfur dioxide $\left(\mathrm{SO}_{2}\right)$ [17], carbon dioxide $\left(\mathrm{CO}_{2}\right)$ [18-19], industrial wastewater, gas and residue [20-21], and other traditional pollutants [22-24]. In addition, literature made one comprehensive weighted composite index with various pollutants to estimate environmental efficiency in China [25].

Studies have made some valuable attempts at environmental efficiency research and laid a theoretical foundation for our research, but there is still room for improvement in this field. Most of the literature focuses on labor, capital, and energy consumption of input variables, and a few papers take total water consumption into the input index in the perspective of the region. Environmental output mainly relates to traditional pollutants such as $\mathrm{SO}_{2}, \mathrm{CO}_{2}$, industrial wastewater, gas, residue, and so on. However, little in the literature has estimated environmental efficiency with consideration of haze, and little has involved energy-saving and haze reduction analysis in China. Therefore, this paper includes total energy consumption, total water consumption, labor, and capital in the index portfolio, and also introduces haze and the main concerned environmental pollutants at the present stage into the comprehensive estimation of environmental efficiency, compared with traditional efficiency measures that only consider GDP, the evaluation result accord with the actual production process, and practical significance and theoretical research value.

\section{Methodology and Data}

\section{Methodology}

In order to fully consider slack movement problem in the input and output variables, this paper applies the DEA method, including undesirable output, to calculate efficiency scores. The SBM-undesirable model is shown as in Formula (1), which is based on the non-radial and non-oriented model by Tone [26].

$$
\begin{gathered}
\rho^{*}=\min \frac{1-\frac{1}{m} \sum_{i=1}^{m} \frac{s_{i}^{-}}{x_{i 0}}}{1+\frac{1}{S_{1}+S_{2}}\left(\sum_{r=1}^{S_{1}} \frac{S_{r}^{g}}{y_{r_{0}}^{g}}+\sum_{r=1}^{S_{2}} \frac{S_{r}^{b}}{y_{r 0}^{b}}\right)} \\
\text { s.t. }\left\{\begin{array}{l}
x_{0}=X \lambda+s^{-} \\
y_{0}^{g}=Y^{g} \lambda-s^{g} \\
y_{0}^{b}=Y^{b} \lambda+s^{b} \\
\lambda \geq 0, s^{-} \geq 0, s^{g} \geq 0, s^{b} \geq 0
\end{array}\right.
\end{gathered}
$$

In Formula (1), the vectors $S$ and $S^{b}$ correspond to the excesses in inputs and bad outputs, respectively, while $S^{g}$ highlights shortages in good outputs. The objective function $\rho^{*}$ is strictly decreasing with respect to $S, S^{g}$, and $S^{b}$, and the objective value satisfies $0<\rho^{*} \leq 1$.

Table 1. Statistical description of the samples.

\begin{tabular}{|c|c|c|c|c|}
\hline Main variables & Average & Min & Max & Stedv. \\
\hline Employed persons (10,000 persons) & $2,727.04$ & 268 & $6,554.3$ & $1,681.42$ \\
\hline Total energy consumption (10,000 tce) & $9,902.85$ & 520 & 37,650 & $7,094.89$ \\
\hline Capital stock (100 million yuan) & $5,220.82$ & 198.58 & $33,233.95$ & $5,519.68$ \\
\hline Total water consumption (100 $\left.\mathrm{m}^{3}\right)$ & 192.95 & 19.94 & 590.1 & 136.03 \\
\hline Gdp (100 million yuan) & $7,543.22$ & 295.42 & $42,881.67$ & $7,095.44$ \\
\hline PM2.5 concentration $\left(\mathrm{ug} / \mathrm{m}^{3}\right)$ & 29.06 & 5.91 & 84.63 & 14.92 \\
\hline
\end{tabular}

Data Source: The indicators data except PM2.5 are obtained from City Statistical Yearbook (2002-13), China Energy Statistics

Yearbook (2002-13), and the China statistical Yearbook on the Environment (2002-13). 
Table 2. Environmental efficiency scores with the consideration of PM2.5 in China.

\begin{tabular}{|c|c|c|c|c|c|c|c|c|c|c|c|c|}
\hline \multicolumn{13}{|c|}{ Eastern area } \\
\hline Year & 2001 & 2002 & 2003 & 2004 & 2005 & 2006 & 2007 & 2008 & 2009 & 2010 & 2011 & 2012 \\
\hline Beijing & 1.000 & 1.000 & 1.000 & 1.000 & 1.000 & 1.000 & 1.000 & 1.000 & 1.000 & 1.000 & 1.000 & 1.000 \\
\hline Tianjin & 1.000 & 1.000 & 1.000 & 1.000 & 1.000 & 1.000 & 1.000 & 1.000 & 1.000 & 1.000 & 1.000 & 1.000 \\
\hline Hebei & 0.608 & 0.607 & 0.586 & 0.596 & 0.591 & 0.571 & 0.567 & 0.548 & 0.541 & 0.538 & 0.450 & 0.448 \\
\hline Fujian & 1.000 & 1.000 & 1.000 & 0.906 & 0.821 & 0.820 & 0.772 & 0.790 & 0.804 & 0.836 & 0.639 & 0.636 \\
\hline Guangdong & 1.000 & 1.000 & 1.000 & 1.000 & 1.000 & 1.000 & 1.000 & 1.000 & 1.000 & 1.000 & 1.000 & 1.000 \\
\hline Hainan & 1.000 & 1.000 & 1.000 & 1.000 & 1.000 & 1.000 & 1.000 & 1.000 & 1.000 & 1.000 & 1.000 & 1.000 \\
\hline Jiangsu & 0.675 & 0.700 & 0.652 & 0.678 & 0.655 & 0.637 & 0.638 & 0.651 & 0.651 & 0.664 & 0.649 & 0.669 \\
\hline Liaoning & 1.000 & 1.000 & 1.000 & 1.000 & 1.000 & 1.000 & 1.000 & 1.000 & 1.000 & 1.000 & 0.680 & 0.670 \\
\hline Shandong & 1.000 & 1.000 & 1.000 & 1.000 & 1.000 & 1.000 & 1.000 & 1.000 & 1.000 & 1.000 & 1.000 & 1.000 \\
\hline Zhejiang & 1.000 & 1.000 & 1.000 & 1.000 & 0.916 & 0.901 & 0.855 & 0.862 & 0.829 & 0.845 & 0.761 & 0.758 \\
\hline Shanghai & 1.000 & 1.000 & 1.000 & 1.000 & 1.000 & 1.000 & 1.000 & 1.000 & 1.000 & 1.000 & 1.000 & 1.000 \\
\hline \multicolumn{13}{|c|}{ Central area } \\
\hline Year & 2001 & 2002 & 2003 & 2004 & 2005 & 2006 & 2007 & 2008 & 2009 & 2010 & 2011 & 2012 \\
\hline Anhui & 0.487 & 0.508 & 0.498 & 0.504 & 0.486 & 0.473 & 0.453 & 0.435 & 0.419 & 0.407 & 0.373 & 0.372 \\
\hline Henan & 0.554 & 0.586 & 0.561 & 0.558 & 0.509 & 0.501 & 0.470 & 0.456 & 0.454 & 0.440 & 0.396 & 0.393 \\
\hline Heilongjiang & 1.000 & 1.000 & 1.000 & 1.000 & 1.000 & 1.000 & 1.000 & 1.000 & 1.000 & 1.000 & 1.000 & 1.000 \\
\hline Hubei & 0.434 & 0.479 & 0.471 & 0.431 & 0.405 & 0.412 & 0.438 & 0.409 & 0.419 & 0.402 & 0.374 & 0.379 \\
\hline Hunan & 0.536 & 0.524 & 0.496 & 0.498 & 0.488 & 0.479 & 0.485 & 0.478 & 0.478 & 0.474 & 0.427 & 0.421 \\
\hline Jilin & 1.000 & 0.863 & 0.768 & 0.911 & 1.000 & 0.909 & 0.918 & 0.692 & 0.709 & 0.804 & 0.471 & 0.469 \\
\hline Jiangxi & 0.604 & 0.588 & 0.544 & 0.538 & 0.532 & 0.489 & 0.481 & 0.463 & 0.456 & 0.462 & 0.409 & 0.413 \\
\hline Shanxi & 0.605 & 0.617 & 0.643 & 0.696 & 0.642 & 0.598 & 0.590 & 0.510 & 0.463 & 0.446 & 0.371 & 0.365 \\
\hline \multicolumn{13}{|c|}{ Western area } \\
\hline Year & 2001 & 2002 & 2003 & 2004 & 2005 & 2006 & 2007 & 2008 & 2009 & 2010 & 2011 & 2012 \\
\hline Gansu & 0.511 & 0.535 & 0.515 & 0.560 & 0.567 & 0.559 & 0.553 & 0.543 & 0.529 & 0.534 & 0.438 & 0.444 \\
\hline Guangxi & 0.529 & 0.556 & 0.519 & 0.468 & 0.481 & 0.451 & 0.448 & 0.427 & 0.392 & 0.369 & 0.334 & 0.330 \\
\hline Guizhou & 0.371 & 0.377 & 0.380 & 0.360 & 0.374 & 0.368 & 0.378 & 0.370 & 0.364 & 0.384 & 0.366 & 0.372 \\
\hline Inner Mongolia & 1.000 & 1.000 & 1.000 & 1.000 & 1.000 & 1.000 & 1.000 & 1.000 & 1.000 & 1.000 & 0.481 & 0.455 \\
\hline Ningxia & 1.000 & 1.000 & 1.000 & 1.000 & 0.606 & 0.607 & 0.596 & 1.000 & 0.555 & 0.580 & 0.514 & 0.522 \\
\hline Qinghai & 1.000 & 1.000 & 1.000 & 1.000 & 1.000 & 1.000 & 1.000 & 1.000 & 1.000 & 1.000 & 1.000 & 1.000 \\
\hline Shaanxi & 0.530 & 0.595 & 0.533 & 0.503 & 0.486 & 0.482 & 0.504 & 0.504 & 0.480 & 0.472 & 0.405 & 0.400 \\
\hline Sichuan & 0.618 & 0.581 & 0.585 & 0.581 & 0.597 & 0.566 & 0.602 & 0.568 & 0.572 & 0.543 & 0.470 & 0.474 \\
\hline Xinjiang & 0.585 & 0.555 & 0.539 & 0.545 & 0.553 & 0.521 & 0.519 & 0.511 & 0.473 & 0.472 & 0.369 & 0.359 \\
\hline Yunnan & 0.630 & 0.623 & 0.620 & 0.577 & 0.571 & 0.561 & 0.546 & 0.539 & 0.538 & 0.477 & 0.446 & 0.420 \\
\hline Chongqing & 0.653 & 0.647 & 0.611 & 0.536 & 0.500 & 0.478 & 0.482 & 0.475 & 0.472 & 0.467 & 0.445 & 0.452 \\
\hline Average & 0.764 & 0.765 & 0.751 & 0.748 & 0.726 & 0.713 & 0.710 & 0.708 & 0.687 & 0.687 & 0.609 & 0.607 \\
\hline
\end{tabular}

Data source: Computed by MaxDEA5.0 software with SBM-undesirable-VRS model. 
Table 3. Environmental efficiency score without the consideration of PM2.5 in China.

\begin{tabular}{|c|c|c|c|c|c|c|c|c|c|c|c|c|}
\hline \multicolumn{13}{|c|}{ Eastern area } \\
\hline Year & 2001 & 2002 & 2003 & 2004 & 2005 & 2006 & 2007 & 2008 & 2009 & 2010 & 2011 & 2012 \\
\hline Beijing & 1.000 & 1.000 & 1.000 & 1.000 & 1.000 & 1.000 & 1.000 & 1.000 & 1.000 & 1.000 & 1.000 & 1.000 \\
\hline Tianjin & 1.000 & 1.000 & 1.000 & 1.000 & 1.000 & 1.000 & 1.000 & 1.000 & 1.000 & 1.000 & 1.000 & 1.000 \\
\hline Hebei & 0.710 & 0.738 & 0.738 & 0.782 & 0.828 & 0.851 & 0.826 & 0.802 & 0.800 & 0.791 & 0.774 & 0.772 \\
\hline Fujian & 1.000 & 1.000 & 0.958 & 0.947 & 0.920 & 0.926 & 0.930 & 0.916 & 0.902 & 0.897 & 0.875 & 0.879 \\
\hline Guangdong & 1.000 & 1.000 & 1.000 & 1.000 & 1.000 & 1.000 & 1.000 & 1.000 & 1.000 & 1.000 & 1.000 & 1.000 \\
\hline Hainan & 1.000 & 1.000 & 1.000 & 1.000 & 1.000 & 1.000 & 1.000 & 1.000 & 1.000 & 1.000 & 1.000 & 1.000 \\
\hline Jiangsu & 0.904 & 0.934 & 0.928 & 0.900 & 0.818 & 0.830 & 0.837 & 0.857 & 0.908 & 0.938 & 0.967 & 0.994 \\
\hline Liaoning & 1.000 & 1.000 & 1.000 & 1.000 & 1.000 & 0.995 & 0.948 & 0.919 & 0.906 & 0.889 & 0.892 & 0.888 \\
\hline Shandong & 1.000 & 1.000 & 1.000 & 1.000 & 1.000 & 1.000 & 1.000 & 1.000 & 1.000 & 1.000 & 1.000 & 1.000 \\
\hline Zhejiang & 1.000 & 1.000 & 1.000 & 1.000 & 0.997 & 0.976 & 0.952 & 0.987 & 0.965 & 0.968 & 0.963 & 0.963 \\
\hline Shanghai & 1.000 & 1.000 & 1.000 & 1.000 & 1.000 & 1.000 & 1.000 & 1.000 & 1.000 & 1.000 & 1.000 & 1.000 \\
\hline \multicolumn{13}{|c|}{ Central area } \\
\hline Year & 2001 & 2002 & 2003 & 2004 & 2005 & 2006 & 2007 & 2008 & 2009 & 2010 & 2011 & 2012 \\
\hline Anhui & 0.777 & 0.849 & 0.899 & 0.890 & 0.871 & 0.838 & 0.812 & 0.804 & 0.814 & 0.816 & 0.823 & 0.840 \\
\hline Henan & 0.803 & 0.846 & 0.859 & 0.869 & 0.850 & 0.840 & 0.767 & 0.727 & 0.701 & 0.663 & 0.634 & 0.617 \\
\hline Heilongjiang & 0.871 & 0.886 & 0.925 & 0.964 & 0.990 & 0.972 & 0.937 & 0.924 & 0.890 & 0.886 & 0.894 & 0.897 \\
\hline Hubei & 0.592 & 0.594 & 0.615 & 0.631 & 0.666 & 0.667 & 0.670 & 0.684 & 0.704 & 0.713 & 0.719 & 0.729 \\
\hline Hunan & 0.816 & 0.879 & 0.907 & 0.932 & 0.966 & 0.946 & 0.924 & 0.910 & 0.916 & 0.900 & 0.892 & 0.898 \\
\hline Jilin & 0.958 & 0.950 & 0.945 & 0.932 & 0.887 & 0.813 & 0.751 & 0.682 & 0.656 & 0.619 & 0.605 & 0.624 \\
\hline Jiangxi & 0.971 & 0.978 & 0.957 & 0.899 & 0.861 & 0.806 & 0.758 & 0.771 & 0.774 & 0.780 & 0.789 & 0.811 \\
\hline Shanxi & 0.922 & 0.946 & 0.976 & 0.981 & 0.967 & 0.928 & 0.912 & 0.878 & 0.803 & 0.767 & 0.732 & 0.726 \\
\hline \multicolumn{13}{|c|}{ Western area } \\
\hline Year & 2001 & 2002 & 2003 & 2004 & 2005 & 2006 & 2007 & 2008 & 2009 & 2010 & 2011 & 2012 \\
\hline Gansu & 0.709 & 0.729 & 0.788 & 0.800 & 0.818 & 0.804 & 0.798 & 0.802 & 0.810 & 0.811 & 0.825 & 0.868 \\
\hline Guangxi & 0.964 & 0.997 & 0.980 & 0.968 & 0.958 & 0.877 & 0.805 & 0.754 & 0.687 & 0.641 & 0.624 & 0.610 \\
\hline Guizhou & 0.636 & 0.627 & 0.635 & 0.642 & 0.667 & 0.662 & 0.671 & 0.683 & 0.695 & 0.697 & 0.717 & 0.736 \\
\hline Inner Mongolia & 1.000 & 1.000 & 1.000 & 0.906 & 0.855 & 0.814 & 0.762 & 0.752 & 0.721 & 0.673 & 0.636 & 0.598 \\
\hline Ningxia & 1.000 & 1.000 & 1.000 & 1.000 & 0.958 & 0.962 & 0.898 & 1.000 & 0.879 & 0.948 & 0.916 & 0.907 \\
\hline Qinghai & 1.000 & 1.000 & 1.000 & 1.000 & 1.000 & 1.000 & 1.000 & 1.000 & 1.000 & 1.000 & 1.000 & 1.000 \\
\hline Shaanxi & 0.721 & 0.785 & 0.737 & 0.712 & 0.738 & 0.731 & 0.740 & 0.740 & 0.744 & 0.715 & 0.696 & 0.692 \\
\hline Sichuan & 0.692 & 0.728 & 0.759 & 0.777 & 0.806 & 0.788 & 0.779 & 0.754 & 0.774 & 0.787 & 0.811 & 0.837 \\
\hline Xinjiang & 0.845 & 0.798 & 0.780 & 0.763 & 0.744 & 0.696 & 0.695 & 0.715 & 0.712 & 0.698 & 0.696 & 0.686 \\
\hline Yunnan & 0.828 & 0.853 & 0.860 & 0.847 & 0.795 & 0.748 & 0.749 & 0.775 & 0.768 & 0.709 & 0.675 & 0.664 \\
\hline Chongqing & 0.925 & 0.897 & 0.848 & 0.794 & 0.779 & 0.739 & 0.725 & 0.728 & 0.751 & 0.760 & 0.774 & 0.802 \\
\hline Average & 0.888 & 0.900 & 0.903 & 0.898 & 0.891 & 0.874 & 0.855 & 0.852 & 0.843 & 0.836 & 0.831 & 0.835 \\
\hline
\end{tabular}

Data source: Computed by MaxDEA5.0 software with BCC-VRS model. 
Input and output variables

- Input variables: On the basis of literature research, the authors select employed persons [13], total energy consumption [27], capital stock [12], and total water consumption [16] as input indicators.

- Output variables: Output variables can be divided into desirable output and undesirable output, desirable output is economic output, this paper selects regional GDP as a proxy index [21]. Undesirable output is the environmental output, and therefore the authors choose haze as a proxy index. Furthermore, because haze was the main object in this paper, and PM2.5 is the key revealed index of haze, the authors decided to select average PM2.5 concentrations as a proxy indicator.

\section{Data and Descriptive Statistics}

Due to the absence of relevant data, Tibet was not considered in this research. This paper selects 30 provinces in the Chinese mainland from 2001 to 2012 [11, 28]. And to examine the imbalance of regional development, this paper also takes the division of China's eastern, central, and western regions according to the National Bureau of Statistics of the People's Republic of China.

The annual data of employed persons, total energy consumption, total water consumption, and GDP are obtained from City Statistical Yearbook (2002-13), the China Energy Statistics Yearbook (2002-13), and the China Statistical Yearbook on the Environment (200213). GDP are smooth measured in 2000 constant prices. The annual data on capital stock of each region of China comes from the results proposed by Shan [29]. The authors assume the depreciation rate at $10.96 \%$, get capital stock in 1952 constant prices (according to the perpetual inventory method in order to get to years of constant), and processed it in 2000 constant prices. The formula is expressed as Formula (2).

$$
K_{i t}=I_{i t}+(1-\delta) K_{i t-1}
$$

...where $K_{i t}$ is the capital stock of $\mathrm{i}$ region in t year, $I_{i t}$ is investment of $i$ region in $\mathrm{t}$ year, and $\delta$ is the depreciation rate of $i$ region in $t$ year.

The annual data of PM2.5 concentration used in this research is estimated from the combination of Moderate Resolution Imaging SpectroRadiometer (MODIS) and Multi-angle Imaging SpectroRadiometer (MISR) AOD (aerosol optical depth) with aerosol vertical profiles and scattering properties [30]. The global PM2.5 concentration dataset has a spatial resolution of $10 \mathrm{~km}$ as annual average during the period of 2001 to 2012 [31]. In this study, the authors obtain PM2.5 concentration during the period of 2001 to 2012 in China's 30 provinces by Arcgis 10.0 software. The statistical descriptions of input and output indicators are in Table 1.

\section{Results and Discussion}

On the base of input and output data of different regions in China during the period of 2001 to 2012, with MaxDEA5.0 software, the authors first use Model (1) to calculate the environmental efficiency score with consideration of PM2.5 of China provinces, as shown in Table 2. In order to make a clearer comparative analysis of the efficiency score without consideration of PM2.5, the authors calculated the efficiency score with BCC-VRS model, as shown in Table 3.

\section{Overall Efficiency Trends}

Fig. 1 shows intuitively the trend of average technical efficiency change in China during 2001-12. The overall environmental efficiency level of China is not high and changes slowly with or without the consideration of PM2.5. Both of them keep synchronized change and present a decreasing trend, and the average environmental efficiency level value is 0.706 with the consideration of PM2.5, the score is significantly lower than the average environmental efficiency score of 0.867 without the consideration of PM2.5. From 2001 to 2010, the efficiency value falls gently, but it declines significantly because of PM2.5 levels increasing sharply in China from 2011, while obvious fluctuations don't appear on technical efficiency without the consideration of PM2.5. Therefore, the authors speculate that haze has to a great extent caused distortion on environmental efficiency estimation. Roughly speaking, if haze is not considered, the economic mode is high-output and high-pollution; if considered, it is high-output but low-pollution. In order to realize economic growth and quality growth, it is necessary to introduce haze into the environmental efficiency estimation framework in China.

\section{Discoveries on the Regional Environmental Efficiency Variance}

There is an unbalanced development of environmental efficiency in different regions. The following can be determined from Fig. 2:

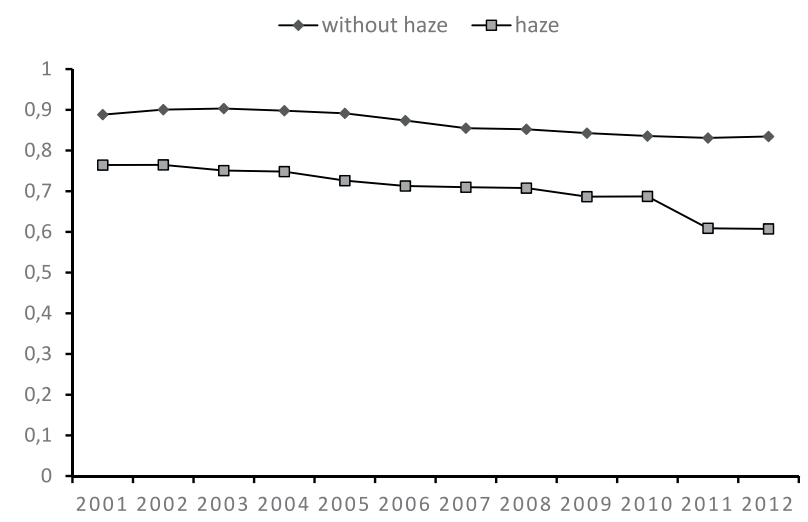

Fig. 1. Average technical efficiency change trend. 


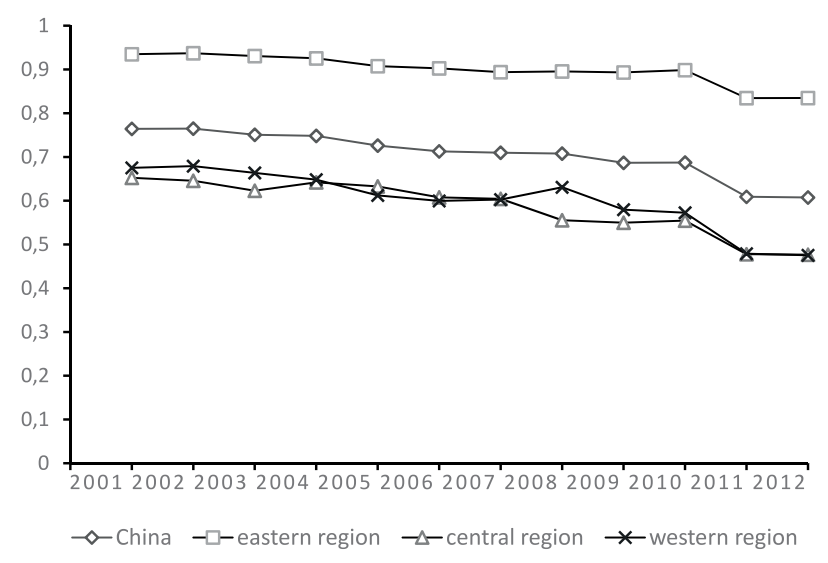

Fig. 2. Environmental efficiency trends in the presence of haze.

- The environmental efficiency values of eastern, central, and western regions with consideration of PM2.5 are $0.899,0.585$, and 0.601 , respectively. There are significant differences with the efficiency score without haze, it has numerical differences for 0.006 , 0.240 , and 0.205 , and the fluctuation of environmental efficiency is unbalanced. Those differences show that environmental efficiencies of different regions are disproportionately affected by haze pollution.

- The environmental efficiency level in the eastern region is higher than average efficiency, showing a negative slightly declining correlation with time. For central and western regions, both of their environmental efficiency levels are lower than the average efficiency at the whole country level, and they present declining cross change during the inspection period.

- The environmental efficiency level in the eastern region is higher than that in the western region, and environmental efficiency of the central region is the worst. The result disagrees with previous studies [13, 27]. In their research, they use traditional undesirable outputs like $\mathrm{CO}_{2}, \mathrm{SO}_{2}$, waste gas emission, wastewater discharge, and solid waste emission to estimate environmental efficiency, and found that the environmental efficiency level in the eastern region is highest among the three regions while the western is worst. This may be because PM2.5 concentration in the central region is $32.62 \mathrm{ug} / \mathrm{m}^{3}$, which is much higher than $21.24 \mathrm{ug} / \mathrm{m}^{3}$ in the western region. Although the central area has a slightly better developed economy than the western region, the eastern region's environmental efficiency is less affected by haze pollution than the western region.

Environmental efficiency can be significantly improved in provinces. The following can be found from Table 2:

- From the time-varying perspective, there are 14 provinces (Beijing, Tianjin, Fujian, Guangdong, Hainan, Liaoning, Shandong, Zhejiang, Shanghai, Heilongjiang, Jilin, Inner Mongolia, Ningxia, and Qinghai) on the production frontier in 2001. Among them there are eight provinces on the boundary of the production in 2012 (Beijing, Tianjin, Guangdong, Hainan, Heilongjiang, Shandong, Shanghai, and Qinghai). DEA efficient provinces have fallen by $42.85 \%$, which can reflect how environmental efficiency declined due to haze during the period of the research sample.

- From the cross-sectional perspective, the eight provinces (Beijing, Tianjin, Guangdong, Hainan, Heilongjiang, Shandong, Shanghai, and Qinghai) are on the border of production for all years and had the best efficiency in all the provinces. Among the eight provinces, six are in the eastern region, Heilongjiang is the central province, and Qinghai is the western province. It is worth mentioning that environmental efficiency of Qinghai is on the production frontier in the entire inspection period, probably because the average PM2.5 concentration of this province is relatively low with only $10.15 \mathrm{ug} / \mathrm{m}^{3}$, and it gets to the standards of air quality according to the World Health Organization (WHO) regulations, although China's air standards are higher than the world's.

- The 14 provinces (Guizhou, Hubei, Guangxi, Anhui, Hunan, Henan, Shaanxi, Jiangxi, Xinjiang, Chongqing, Gansu, Shanxi, Yunnan, and Hebei) have bad environmental efficiencies. One important reason is that haze pollution is heavy in these provinces, and many energy-intensive industries such as steel, cement, and building materials consume massively polluting fossil energy [11,23].

\section{Results of Wilcoxon Rank Sum Test}

In order to test deviation for environmental efficiency with or without the consideration of PM2.5 and to realize the changes more clearly, we conducted the Wilcoxon rank sum test.

The null hypothesis is H0: There are no significant differences on China's provincial environmental efficiency estimation results with or without the consideration of PM2.5.

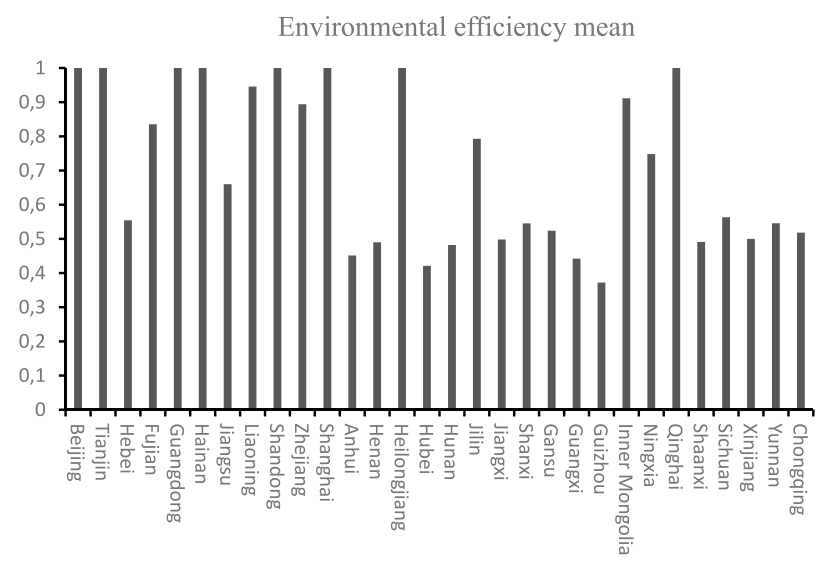

Fig. 3. Environmental efficiency means of each province. 


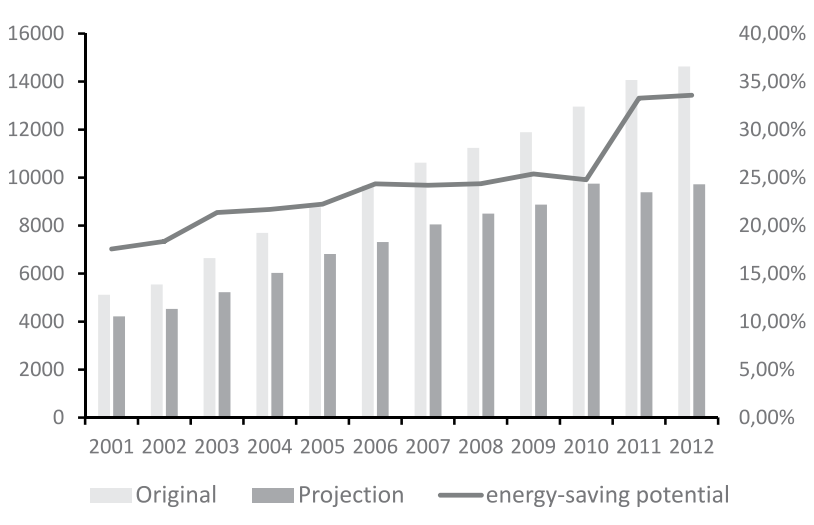

Fig. 4. Average energy savings potential in various provinces during 2001-12.

The alternative hypothesis is $\mathrm{H} 1$ : There are significant differences on China's provincial environmental efficiency estimation results with or without the consideration of PM2.5.

The authors take Wilcoxon Rank Sum test on the environmental efficiency by SPSS18.0, and the results are shown in Table 4, indicating that there are obvious differences between China's provincial environmental efficiency with or without the consideration of PM2.5 and the significance level is $1 \%$. Therefore, the null hypothesis is rejected and the alternative hypothesis is accepted. This suggests that the environmental efficiency estimation was biased if haze - the main concerned environmental pollutant at the present stage - was excluded. This result agrees with some empirical studies that the value of the conventional productivity was higher than the average annual productivity growth, including undesirable outputs $[12,17,32-33]$. However, this finding disagrees with some research that excludes emissions results in understating efficiency growth [34-35]. In their studies, environmental regulation brought improvements for entity efficiency when those undesirable outputs are considered.

\section{Analyzing Energy-Saving and Haze Reduction}

According to the SBM-undesirable-VRS model, the authors calculate the redundant degree of ineffective provinces and municipalities, which means input and output should be reduced or increased according to the slack variables in order to achieve effective sample standard. We focus on calculating redundancy degree of energy consumption, water consumption, and haze pollution for the invalid provinces.

Overall, there is a large improvement ability for energy consumption, water consumption, and haze emission of various provinces and cities in China. It can be seen from Fig. 4 that there is $24.26 \%$ of energy saving potential on average of the study period. The lowest energy savings rate was $17.56 \%$ in 2001 , while the highest was $33.58 \%$ in 2012. With the increases of energy consumption, the energy saving potential becomes

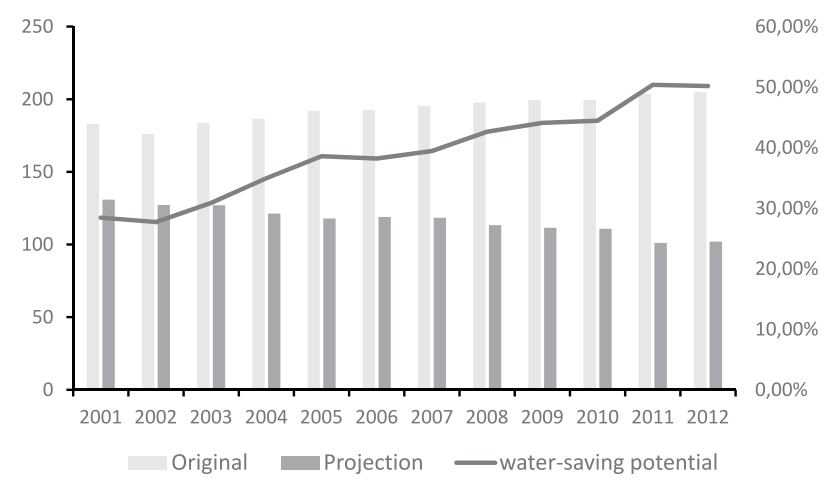

Fig. 5. Average water savings potential in various provinces during 2001-12.

higher. This indicates that environmental efficiency can be improved by reducing energy consumption. For the study samples, there could be 304.32 million tons coal saved during 2001-12. Economic growth depends mainly on the material energy consumption rather than science and technology progress, high-quality talents, and management innovation. The outdated production equipment and technology cause a large amount of energy waste. At the same time, the coal-dominated energy structure is not conducive to environmental efficiency improvements, but also has a negative impact on energy utilization efficiency. As a result, China has a long way to go to achieve energy conservation.

Fig. 5 shows that there is $39.16 \%$ of regional water saving potential on average during the study period. The lowest water saving rate was $28.44 \%$ in 2001 while the highest was $50.18 \%$ in 2012 , and the water-saving potential in 2012 was $22 \%$ higher than in 2001. There could be 7.62 billion $\mathrm{m}^{3}$ on average saved during 2001-12. With more water consumption, the water-saving potential is becoming bigger and bigger. The water-saving potential even reached $50 \%$, and almost half of the water resources are wasted. Water use efficiency is not high, and the degree of industrial water reuse and recycling is low and water technology is outdated. According to data shown in 2004, the industrial water reuse rate in China was only

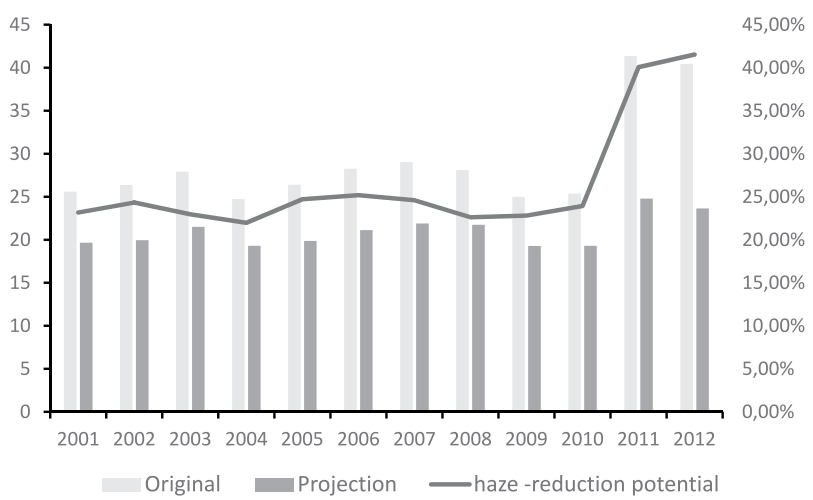

Fig. 6. Average haze reduction potential in various provinces during 2001-12. 
Table 4. Wilcoxon rank sum test results.

\begin{tabular}{|c|c|c|c|}
\hline Wilcoxon rank sum test & Statistics & $\mathrm{P}$ & Decision \\
\hline Environmental efficiency & $-2.354 * *$ & 0.019 & Reject \\
\hline
\end{tabular}

Note:** indicates a significance level of $5 \%$
$60-65 \%$, and $20 \%$ lower compared with the rate of 80 $85 \%$ in developed countries. Therefore, water-saving potential should be a priority in the future.

Fig. 6 shows that regional haze reduction potential is $26.49 \%$ on average. The rate of haze reduction was $23.16 \%$ in 2001, then fluctuated up and down but has risen sharply

Table 5. Average amount adjusted of environmental efficiency during 2001-12.

\begin{tabular}{|c|c|c|c|c|c|c|}
\hline DMU & $\begin{array}{c}\text { Employed } \\
\text { Persons }\end{array}$ & $\begin{array}{c}\text { Total energy } \\
\text { Consumption }\end{array}$ & $\begin{array}{l}\text { Capital } \\
\text { Stock }\end{array}$ & $\begin{array}{c}\text { Total water } \\
\text { Consumption }\end{array}$ & GDP & PM2.5 \\
\hline Units & 10,000 Persons & 10,000 tce & 100 million yuan & $100 \mathrm{~m}^{3}$ & 100 million yuan & $\mathrm{ug} / \mathrm{m}^{3}$ \\
\hline Anhui & $-2,630.39$ & $-2,436.31$ & -184.12 & -168.03 & 0.00 & -27.09 \\
\hline Beijing & 0.00 & 0.00 & 0.00 & 0.00 & 0.00 & 0.00 \\
\hline Fujian & -398.77 & -276.70 & $-1,423.00$ & -64.07 & 0.00 & -1.26 \\
\hline Gansu & -901.76 & $-2,135.76$ & -299.16 & -72.75 & 0.00 & -3.21 \\
\hline Guangdong & 0.00 & 0.00 & 0.00 & 0.00 & 0.00 & 0.00 \\
\hline Guangxi & $-1,813.80$ & $-1,939.36$ & $-2,410.92$ & -227.30 & 0.00 & -15.28 \\
\hline Guizhou & $-1,589.17$ & $-4,432.01$ & $-1,022.42$ & -56.87 & 0.00 & -13.53 \\
\hline Hainan & 0.00 & 0.00 & 0.00 & 0.00 & 0.00 & 0.00 \\
\hline Heibei & $-1,801.96$ & $-12,485.29$ & $-2,775.50$ & -65.50 & 0.00 & -11.78 \\
\hline Henan & $-3,709.47$ & $-7,165.26$ & $-6,428.68$ & -69.57 & 0.00 & -27.67 \\
\hline Heilongjiang & 0.00 & 0.00 & 0.00 & 0.00 & 0.00 & 0.00 \\
\hline Hubei & $-2,124.14$ & $-5,070.67$ & $-2,014.11$ & -216.68 & 0.00 & -16.12 \\
\hline Hunan & $-2,240.78$ & $-4,106.06$ & -243.17 & -192.67 & 0.00 & -20.64 \\
\hline Jilin & -230.21 & $-1,082.30$ & $-3,520.51$ & -29.65 & 0.00 & -1.65 \\
\hline Jiangsu & -519.70 & $-2,632.68$ & $-8,233.87$ & -177.80 & 0.00 & -24.20 \\
\hline JIangxi & $-1,445.69$ & $-1,160.39$ & -522.64 & -156.74 & 0.00 & -15.46 \\
\hline Liaoning & -25.88 & $-1,614.58$ & $-1,133.82$ & -1.51 & 0.00 & -2.61 \\
\hline Inner Mongolia & -51.78 & -2520.85 & -1751.00 & -24.71 & 0.00 & -0.13 \\
\hline Ningxia & -2.34 & -598.04 & -34.20 & -23.66 & 167.08 & -5.86 \\
\hline Qinghai & 0.00 & 0.00 & 0.00 & 0.00 & 0.00 & 0.00 \\
\hline Shandong & 0.00 & 0.00 & 0.00 & 0.00 & 0.00 & 0.00 \\
\hline Shanxi & -775.11 & $-8,946.95$ & $-1,148.67$ & -14.14 & 0.00 & -13.07 \\
\hline Shaanxi & $-1,318.42$ & $-2,462.77$ & $-1,758.71$ & -47.46 & 0.00 & -10.34 \\
\hline Shanghai & 0.00 & 0.00 & 0.00 & 0.00 & 0.00 & 0.00 \\
\hline Sichuan & $-3,052.26$ & $-6,043.54$ & $-1,950.33$ & -88.20 & 0.00 & -3.61 \\
\hline Tianjin & 0.00 & 0.00 & 0.00 & 0.00 & 0.00 & 0.00 \\
\hline Xinjiang & -175.38 & $-3,520.01$ & $-1,788.18$ & -470.31 & 0.00 & -3.43 \\
\hline Yunnan & $-1,733.98$ & $-2,631.20$ & $-1,268.93$ & -80.92 & 0.00 & -1.71 \\
\hline Zhejiang & -485.67 & $-1,239.88$ & -909.70 & -2.31 & 0.00 & -3.68 \\
\hline Chongqing & -971.43 & $-1,579.14$ & -955.97 & -34.52 & 0.00 & -18.93 \\
\hline Average & -933.27 & $-2,535.99$ & $-1,392.59$ & -76.18 & 5.57 & -8.04 \\
\hline
\end{tabular}

Data source: Computed by MaxDEA5.0 software with SBM-undesirable-VRS model. 
since 2011 , when it reached $40.07 \%$. The reduction degree of haze was $41.53 \%$ in 2012 , increased by $20 \%$ compared with 2001. There could be $8.04 \mathrm{ug} / \mathrm{m}^{3}$ in average saved during 2001-12. All of these show that haze pollution was serious in China, and there is a huge potential on haze reduction.

From 2003 to 2005 and 2007 to 2010, there were two slight declining trends and two bottoms appear in 2004 and 2008. This was a result of government policies and investments on air pollution control. For example, the environmental protection agency drew 113 key cities for air pollution control in 2002 according to The Law about Prevention and Treatment of Air Pollution. The standard of environmental air quality monitoring (try out) was carried out in 2007. This attempt laid a certain foundation for atmospheric pollution governance and achieved a certain effect. Besides, the investment -14.28 billion RMB in 2004 and 27.53 billion RMB in 2007 also played a guarantee role in controlling haze pollution. However, the failure of old environmental policy, the small investment scale, and the environmental bearing capacity couldn't match the huge pollution emissions after 2010, which led to haze pollution overall outbreak in 2011 and 2012. Therefore, it is critical to formulate environmental standards and environmental policy and enforce policies for haze governance.

\section{The Improvement Direction of Environmental Efficiency}

Since the SBM-undesirable model utilizes slacks on input or output variables to measure the environmental efficiency for each Chinese region, the inefficient regions can become efficient by adjusting their input and output variables so as to reach the benchmark [27-28, 34]. Therefore, in this section the authors use the SBMundesirable model to survey the improvement direction of environmental efficiency for different Chinese regions during our study period. Table 5 shows the average amount adjusted for environmental efficiency during our study period.

In Table 5, every province has to adjust its input and output variables to reach the benchmark. The input variables of employed persons, total energy consumption, capital stock, and total water consumption can be reduced by 9.33 million persons, 25.36 million tons of SCE, 139.26 billion yuan, and 7.62 billion $\mathrm{m}^{3}$, respectively. And the desirable output of GDP can increase 5.57 trillion yuan and the undesirable output of PM2.5 can reduce $8.04 \mathrm{ug} / \mathrm{m}^{3}$.

Specifically, Beijing, Guangdong, Hainan, Heilongjiang, Qinghai, Shandong, Shanghai, Tianjin, only environmental efficiency of these eight provinces and cities can reach the production frontier, the input and output variables of the rest of the provinces require different degrees of adjustment. The authors take Hebei Province as an example, if its environmental efficiency wants to become efficient, employed persons, total energy consumption, capital stock, and total water consumption needs be reduced by 18.02 million persons, 124.85 million tce, 277.55 billion yuan, and 6.55 billion $\mathrm{m}^{3}$, respectively, and the mean PM2.5 concentration would be reduced by $11.78 \mathrm{ug} / \mathrm{m}^{3}$.

It is important to note that only the GDP of Ningxia Province can increase 16.71 billion yuan, and other provinces have no adjustment. All of these show that the current technical level is not changed, if the provinces want to improve their environmental efficiency and reach the production frontier, they must focus on employed persons, total energy consumption, capital stock, and total water consumption; specifically, PM2.5 concentration reduction must be a top priority.

In addition, the number reduction of employed persons in Henan, which can reach 37.09 million, is the biggest value in China. The authors think that Henan is the most populous and labor-intensive province in China, and how to make great efforts on personnel placement should be one of the effective ways to improve the environmental efficiency in Henan.

The number reduction of energy consumption in Hebei Province, 124.85 million tce, is the highest value in China. These are closely related with its attribute, and energy-intensive manufacturing occupies a high proportion in Hebei, the iron and steel enterprises are especially concentrated and energy consumption is high in the province. Therefore, adjusting the industrial structure and reducing energy consumption has become one of the main challenges to achieving an efficient frontier in Hebei.

In Jiangsu Province, the reduction of capital stock, 823.39 billion yuan, is the highest value in China. The annual average capital stock is 4.11 trillion yuan in Jiangsu, which is inferior to the 4.36 trillion yuan in Shandong. So, to scale down the capital stock in the first place, Jiangsu cannot only save resources, but also can reach the production frontier.

The reduction of the total water consumption in Xinjiang Province, 47.03 billion $\mathrm{m}^{3}$, is the largest value in China. The annual average amount of total water consumption reached 52.67 billion $\mathrm{m}^{3}$ in Xinjiang, which is only 53.38 billion $\mathrm{m}^{3}$ lower than in Jiangsu. Therefore, Xinjiang needs to scale down total water consumption to become the benchmarking province.

The PM2.5 reduction potential in Henan Province, $27.67 \mathrm{ug} / \mathrm{m}^{3}$, is the higher than many provinces and cities. During our study period, the top three polluted provinces by haze in China are Shandong, Jiangsu, and Henan, where the PM2.5 concentrations are $55.20 \mathrm{ug} / \mathrm{m}^{3}, 53.55 \mathrm{ug} / \mathrm{m}^{3}, 51.07 \mathrm{ug} / \mathrm{m}^{3}$, respectively. In these regions, labor and resources are usually intensive, and especially highly concentrated are high-energy consuming and high-polluting industries such as steel, building materials, metallurgy, chemical, petrochemical, and so on. Therefore, these provinces should pay $\mathrm{s}$ pecial attention to reducing average PM2.5 concentrations and strengthening control haze pollution to achieve effective environmental efficiency. 


\section{Conclusions}

This paper examines environmental efficiency with and without the consideration of PM2.5 and analyzes the energy savings and haze reduction with the SBMundesirable-VRS model based on the provincial panel data of China during 2001-12. The crucial findings are as follows: first and foremost, the overall environmental efficiency score is inefficient, and there is unbalanced regional development among the eastern, central, and western regions. In addition, there exist significant differences between provinces in environmental efficiency. What is more, Wilcoxon's rank sum test also shows that true environmental efficiency was underestimated if PM2.5 was ignored, which indicates that both economic output and haze should be included in the estimation of environmental efficiency levels in China, where haze is the main concerned environmental pollutant at the present stage. Last but not least, there is a large space for energy consumption, water consumption, and haze emissions in China. The inefficient regions can become efficient through adjusting their input and output variables so as to reach the benchmark. To improve environmental efficiency and haze control in the future, policy recommendations can be summarized as follows:

1. To improve environmental efficiency at the national level, China should change the economic development mode of high input, high energy consumption, high pollution, and high emissions and turn toward the ecological development mode of high output, low energy consumption, low pollution, and low emissions, which also considers both economic growth and growth quality.

2. Second, the results show that environmental efficiency is unbalanced in regions and provinces. This means that it is key to set up regional emissions standards and regional coordination mechanisms such as charging different pollution emission taxes according to the degree of economic development in various regions, which is conducive to haze control and would narrow the regional environmental efficiencies gap.

3. The results reflects that there is great potential savings of energy, water, and regional haze reduction. This suggests that the government should eliminate outdated equipment and introduce new technologies to reduce water consumption and the consumption of fossil fuels, and encourage the development and utilization of new and renewable resources of energy. The government also should pay more attention to absorption and utilization in order to avoid wasting resources.

\section{Acknowledgements}

This paper was finished as expected thanks to support by the National Natural Science Foundation of China (Nos. 71272160 and 71673022).

\section{References}

1. MINISTRY OF ENVIRONMENTAL PROTECTION OF THE PEOPLE'S REPUBLIC OF CHINA. 2013 Report on the State of the Environment Status in China; Beijing: China environmental protection center 2014 [In Chinese].

2. WORLD BANK (WASHINGTON, DC). Cost of Pollution in China: Economic Estimates of Physical Damages. World Bank, 2007.

3. MAJEWSKI G., PRZEWOZ'NICZUK W. Study of particulate matter pollution in Warsaw area. Pol. J. Environ. Stud. 18 (2), 293, 2009.

4. ĆWIKLAK K., PASTUSZKA J.S., ROGULAKOZŁOWSKA W. Influence of traffic on parti-culatematter polycyclic aromatic hydrocarbons in urban atmosphere of Zabrze, Poland. Pol. J. Environ. Stud. 18 (4), 579, 2009.

5. BAI Y., BRUGHA R.E., JACOBS L., GRIGG J., NAWROT T.S., NEMERY B. Carbon loading in airway macrophages as a biomarker for individual exposure to particulate matter air pollution-A critical review. Environ. Int. 74 (1), 32, 2015.

6. POKORNÁ P., HOVORKA J., KLÁN M., HOPKE P.K. Source apportionment of size resolved particulate matter at a European air pollution hot spot. Sci. Total. Environ. 502 (1), 172, 2015

7. MILOJEVIC A., WILKINSON P., ARMSTRONG B., BHASKARAN K., SMEETH L., HAJAT S. Short-term effects of air pollution on a range of cardiovascular events in England and Wales: case-crossover analysis of the MINAP database, hospital admissions and mortality. Heart. 100 (14), 1093, 2014.

8. CORREIA A.W., POPE III C.A., DOCKERY D.W., WANG Y., EZZATI M., DOMINICI F. The effect of air pollution control on life expectancy in the United States: an analysis of 545 US counties for the period 2000 to 2007. Epidemiology. 24 (1), 23, 2013.

9. YORIFUJI T., KASHIMA S., TSUDA T., ISHIKAWATAKATA K., OHTA T., TSURUTA K.I., DOI H. Longterm exposure to traffic-related air pollution and the risk of death from hemorrhagic stroke and lung cancer in Shizuoka, Japan. Sci. Total Environ. 443 (1), 397, 2013.

10. PANT P., SHUKLA A., KOHL S.D., CHOW J.C., WATSON, J.G., HARRISON R.M. Characterization of ambient PM2. 5 at a pollution hotspot in New Delhi, India and inference of sources. Atmos. Environ. 109 (5), 178, 2015.

11. MA L., ZHANG X. The Spatial Effect of China's Haze Pollution and the Impact from Economic Change and Energy Structure. Chin. Ind. Econ. 4, 19, 2014. (In Chinese)

12. KANEKO S., MANAGI S. Environmental Productivity in China. Econ. Bull. 17(2):1-10, 2004.

13. SONG M., SONG Y., AN Q., YU H. Review of Environmental Efficiency and Its Influencing Factors in China: 1998-2009. Renew. Sust. Energ. Rev. 20 (4), 8, 2013.

14. WU Y. Analysis of Environmental Efficiency in China's Regional Economies. Presentation at the 6th International Conference Is China's Development Sustainable, 2007.

15. KHOSHNEVISAN B., RAFIEE S., OMID M., MOUSAZADEH H. Applying data envelopment analysis approach to improve energy efficiency and reduce GHG (greenhouse gas) emission of wheat production. Energ. 58 (9), 588, 2013.

16. XIE B.C., SHANG L.F., YANG S.B., YI B.W. Dynamic environmental efficiency evaluation of electric power industries: Evidence from OECD (Organization for Economic Cooperation and Development) and BRIC 
(Brazil, Russia, India and China) countries. Energ. 74 (9), 147, 2014.

17. WATANABE M., TANKA K. Efficiency Analysis of Chinese Industry: a Directional Distance Function Approach. Energy Policy, 35 (12), 6323, 2007.

18. DU L., MAO J. Estimating the environmental efficiency and marginal $\mathrm{CO}_{2}$ abatement cost of coal-fired power plants in China. Energy Policy, 85 (12), 347, 2015.

19. MOUTINHO V., MADALENO M., ROBAINA M. The economic and environmental efficiency assessment in EU cross-country: evidence from DEA and quantile regression approach. Ecol. Indic. 78 (7), 85, 2017.

20. ZHANG X., LI Y., WU W. Evaluation of Urban Resource and Environmental Efficiency in China Based on the DEA Model. J. Resou. \& Ecol. 5 (1), 11, 2014.

21. SONG M.L., ZHANG L.L., LIU W., FISHER R. BootstrapDEA analysis of BRICS' energy efficiency based on small sample data. Appl. Energ. 112 (12), 1049, 2013.

22. SUEYOSHI T., YUAN Y. China's regional sustainability and diversified resource allocation: DEA environmental assessment on economic development and air pollution. Energ. Econ. 49 (8), 239, 2015.

23. CHEN J., SONG M., XU L. Evaluation of environmental efficiency in China using data envelopment analysis. Ecol. Indic. 52 (5), 577, 2015.

24. ZHANG J., ZENG W., SHI H. Regional environmental efficiency in china: analysis based on a regional slack-based measure with environmental undesirable outputs. Ecol. Indic.71 (12), 218, 2016.

25. WANG Z., FENG C. Total-factor energy efficiency calculation and its influencing factors analysis in China. Syst. Engine-Theo. \& Prac. 35 (6), 1361, 2015 [In Chinese].

26. TONE K. A Slacks-based Measure of Efficiency in Data Envelopment Analysis. Eur. J. Oper. Res. 130 (3), 498, 2001.

27. WANG K., YU S., ZHANG W. China's Regional Energy and Environmental efficiency: a DEA Window Analysis based Dynamic Evaluation. Math. Comput. Model. 58 (5):, 1117, 2013.

28. HE F., MA D., ZHU L. Measurement and Factors of Environmental Technology Efficiency in China under the Constraint of Haze. R \& D Management. 28 (5), 34, 2016[In Chinese].

29. SHAN H. Reestimating the Capital Stock of China: 19522006. J. Quant. Tech. Econ. 8, 17, 2008 [In Chinese].

30. VAN DONKELAAR A., MARTIN R.V, BRAUER M., KAHN R., LEVY R., VERDUZCO C., VILLENEUVE P. J. Global estimates of ambient fine particulate matter concentrations from satellite-based aerosol optical depth: development and application. Environ. Health Persp. 118 (6), 847, 2010.

31. BATTELLE MEMORIAL INSTITUTE AND CIESIN. Global annual average PM2.5 grids from MODIS and MISR Aerosol Optical Depth (AOD), 1998-2012. http:// sedac.ciesin.columbia.edu/data/set/sdei-global-annual-avgpm2-5-modis-misr-seawifs-aod-1998-2012/data-download (2015-07-16).

32. RØDSETH K.L. Environmental efficiency measurement and the materials balance condition reconsidered. Eur. J. Oper. Res. 250 (1), 342, 2016.

33. ZHANG C., LIU H., BRESSERS H.T.A, BUCHANAN K.S. Productivity growth and environmental regulationsaccounting for undesirable outputs: Analysis of China's thirty provincial regions using the Malmquist-Luenberger index. Ecol. Econ. 70 (12), 2369, 2011.

34. CHUNG Y.H., FÄRE R., GROSSKOPF S. Productivity and undesirable outputs: a directional distance function approach. J. Environ. Manage. 51(3): 229-240, 1997.

35. HE F., ZHANG Q., LEI J., FU W., XU X. Energy efficiency and productivity change of China's iron and steel industry: Accounting for undesirable outputs. Energy Policy. 54 (3), 204, 2013. 